\title{
Monitoring and management of lung cancer patients following curative-intent treatment: clinical utility of 2-deoxy-2-[fluorine-18]fluoro-d-glucose positron emission tomography/computed tomography
}

\author{
This article was published in the following Dove Press journal: \\ Lung Cancer:Targets and Therapy \\ 27 April 2016 \\ Number of times this article has been viewed
}

\section{Shigeki Sawada \\ Hiroshi Suehisa \\ Tsuyoshi Ueno \\ Ryujiro Sugimoto \\ Motohiro Yamashita}

Department of Thoracic Surgery, National Hospital Organization Shikoku Cancer Center, Matsuyama, Japan
Correspondence: Shigeki Sawada

Department of Thoracic Surgery,

Shikoku Cancer Center, 160 Kou,

Minamiumemoto-cho, Matsuyama, Ehime

791-0280, Japan

$\mathrm{Tel}+8 \mathrm{I} 89999$ IIII

Fax +81899991100

Emailssawada@shikoku-cc.go.jp
Abstract: A large number of studies have demonstrated that 2-deoxy-2-[fluorine-18]fluoroD-glucose positron emission tomography/computed tomography (FDG-PET/CT) is superior to conventional modalities for the diagnosis of lung cancer and the evaluation of the extent of the disease. However, the efficacy of PET/CT in a follow-up surveillance setting following curative-intent treatments for lung cancer has not yet been established. We reviewed previous papers and evaluated the potential efficacy of PET-CT in the setting of follow-up surveillance. The following are our findings: 1) PET/CT is considered to be superior or equivalent to conventional modalities for the detection of local recurrence. However, inflammatory changes and fibrosis after treatments in local areas often result in false-positive findings; 2) the detection of asymptomatic distant metastasis is considered to be an advantage of PET/CT in a follow-up setting. However, it should be noted that detection of brain metastasis with PET/CT has some limitation, similar to its use in pretreatment staging; 3 ) additional radiation exposure and higher medical cost arising from the use of PET/CT should be taken into consideration, particularly in patients who might not have cancer after curative-intent treatment and are expected to have a long lifespan. The absence of any data regarding survival benefits and/or improvements in quality of life is another critical issue. In summary, PET/CT is considered to be more accurate and sensitive than conventional modalities for the detection of asymptomatic recurrence after curative-intent treatments. These advantages could modify subsequent management in patients with suspected recurrence and might contribute to the selection of appropriate treatments for recurrence. Therefore, PET/CT may be an alternative to conventional follow-up modalities. However, several important issues remain to be solved. PET/CT in a follow-up surveillance setting is generally not recommended in clinical practice at the moment.

Keywords: lung cancer, follow-up surveillance, FDG-PET/CT

\section{Introduction}

Periodic examinations, including physiologic and radiographic examinations, are usually performed to detect recurrence after curative-intent treatment, and these examinations are commonly referred to as follow-up surveillance. However, the efficacy of 2-deoxy-2-[fluorine-18]fluoro-D-glucose positron emission tomography/ computed tomography (FDG-PET/CT) in a follow-up surveillance setting following curative-intent treatments for lung cancer has not yet been established. In this review, we survey previous papers and evaluate the potential efficacy of FDG-PET/CT in the setting of long-term follow-up surveillance. We first briefly summarize the current 
imaging examinations used for diagnosis or pretreatment staging of lung cancer and conventional follow-up modalities performed after curative-intent treatment. We then review the efficacy of FDG-PET/CT in a follow-up surveillance setting following curative-intent treatments.

\section{Conventional imaging examinations used for diagnosis and pretreatment staging of lung cancer}

Imaging modalities including CT, magnetic resonance imaging (MRI), bone scintigraphy, and abdominal ultrasonography are used for the diagnosis of lung cancer and the evaluation of disease extent. CT is fast and painless and has high spatial resolution, providing excellent morphologic information. ${ }^{1,2}$ The sensitivity and specificity of CT for the diagnosis of lung cancer have been reported as 50\%-90\% and 60\%-90\%, respectively. ${ }^{3,4}$ MRI creates images using a magnetic field and pulses of radiowave energy, providing information regarding the lesion structure different from that obtainable using CT; MRI is more frequently used to detect brain abnormalities. ${ }^{5}$ Combining these modalities can provide a more accurate diagnosis of lung cancer and a more accurate evaluation of the disease extent.

\section{History of FDG-PET or FDG-PET/CT}

PET was initially used as a research tool for brain function studies and the assessment of cardiac metabolism. ${ }^{6-8}$ PET using FDG has been applied in patients with neoplasms. Neoplastic tissues have a much higher rate of glucose consumption than normal tissue or benign lesions. FDG-PET can visualize glucose metabolism, enabling the whole body, excluding the brain, to be examined in a noninvasive manner in addition to enabling the differentiation of malignant and benign lesions with high accuracy. ${ }^{9-13}$ Furthermore, FDG uptake is reportedly correlated with the tumor response to chemotherapy/radiotherapy and patient outcome. ${ }^{14-16}$ Using advanced computer technology, FDG-PET has been integrated with CT and merged as an examination that can provide not only a differential diagnosis between neoplasms and normal tissues but also an accurate location of the lesions. ${ }^{17-19}$ Because of these advantages, FDG-PET or FDG-PET/CT has quickly spread and is now used worldwide for the diagnosis of malignancies and the evaluation of the disease extent. Recently, new radiotracers such as ${ }^{18} \mathrm{~F}$-fluorothymidine or ${ }^{68} \mathrm{Ga}$-Alfatide II have also been studied. ${ }^{18} \mathrm{~F}$-fluorothymidine is an indicator of proliferation, and ${ }^{68} \mathrm{Ga}$-Alfatide II is a marker of neovascularization, and these radiotracers reflect different aspects of malignancy from FDG. ${ }^{20,21}$ PET/CT using new radiotracers might be available in the future.

\section{PET/CT for the diagnosis and staging of lung cancer Diagnosis of lung cancer}

A large number of studies have demonstrated that PET/CT is more accurate than $\mathrm{CT}$ for the diagnosis of lung cancer, with a sensitivity of $\sim 95 \%$ and a specificity of $80 \%{ }^{22,23}$ In contrast, false-positive results are often obtained for inflammatory or granulomatous lesions. ${ }^{24}$ Furthermore, false-negative results can occur in subcentimeter lung cancer or in adenocarcinoma in situ, even those that are $>1 \mathrm{~cm} \cdot{ }^{25,26}$

\section{Evaluation of disease extent}

Mediastinal lymph node metastasis

The approximate sensitivity and specificity of CT for the detection of mediastinal lymph node metastasis were reportedly $50 \%-70 \%$ and $65 \%-85 \%$, respectively, while the corresponding values for PET/CT were $75 \%-85 \%$ and $85 \%-90 \%$, respectively. ${ }^{27,28}$ Thus, $\mathrm{PET} / \mathrm{CT}$ is significantly superior to CT for the diagnosis of mediastinal lymph node metastasis. ${ }^{29-32}$ However, false-positive results were observed in some patients with anthracosilicosis or inflammatory diseases.

\section{Distant metastasis}

The most common sites of metastasis are bones, the adrenal gland, the liver, and the brain. Several studies have demonstrated that PET/CT is superior or equal to conventional modalities for the detection of distant metastasis. ${ }^{32,33}$ However, the ability of PET/CT to detect brain metastasis is significantly limited because of the high level of glucose consumption in the brain, and enhanced MRI remains the gold standard for the detection of brain metastasis. ${ }^{34-36}$

Overall, PET/CT is considered to be superior to conventional modalities for the diagnosis of lung cancer and the evaluation of disease extent. Pieterman et $\mathrm{al}^{32}$ reviewed previous studies and compared PET with $\mathrm{CT}$ in terms of sensitivity and specificity and reported that the use of PET for preoperative staging resulted in a different staging from that determined using conventional modalities in $27 \%-62 \%$ of patients. Upstaging because of the detection of unexpected metastasis using PET was frequently observed. Schrevens et $\mathrm{al}^{37}$ reported that unknown metastases were found using PET in 5\%-29\% of patients with negative conventional staging, and such PET/CT findings could influence a patient's subsequent management, potentially contributing to an improved outcome.

Thus, a large number of studies have demonstrated the superiority of PET/CT over conventional modalities, but most of these studies focused on the efficacy of PET/CT 
in a pretreatment work-up setting; only a few addressed the efficacy of PET/CT in a follow-up surveillance setting. Therefore, we reviewed papers discussing the use of PET/CT in a follow-up surveillance setting following curative-intent treatments and evaluated the potential efficacy and advantage of PET/CT in this setting.

\section{Current recommendations for follow-up surveillance following curative-intent treatment: how often and which modalities?}

Follow-up surveillance is usually performed after curativeintent treatment. The purpose of follow-up surveillance is to detect recurrences and disease progression at an early stage to institute adequate treatment in an attempt to improve the survival duration and quality of life. However, an adequate follow-up schedule outlining when and which examinations should be performed after curative-intent treatment has not yet been established. Furthermore, whether aggressive searches for asymptomatic recurrences through periodic examinations contribute to an improvement in survival has not yet been confirmed. No recent studies have addressed the cost effectiveness of postoperative follow-up examinations, and only the few investigators who had previously evaluated them had questioned the benefit of such examinations in cancer patients from the viewpoints of efficacy and cost effectiveness. ${ }^{38-40}$ On the other hand, some investigators have reported that the survival duration is longer in patients with recurrences detected during the asymptomatic stage than in those with recurrences diagnosed after the onset of symptoms, and that follow-up is useful for the detection of asymptomatic recurrences. . $^{41,42}$

Under these circumstances, several medical societies have individually designed follow-up surveillance guidelines for patient care after curative-intent treatments for lung cancer. While some variations in follow-up modalities and the frequencies of their use exist among the guidelines, all the guidelines recommend the use of chest CT (Table 1). ${ }^{43-46}$ In contrast, none of the guidelines recommends the use of PET/ CT in a follow-up surveillance setting.

\section{PET/CT in a follow-up surveillance setting}

We reviewed studies that used PET/CT as a follow-up examination after curative-intent treatment.

\section{Local recurrence}

\section{Post resection}

The major issue concerning the use of PET/CT in a postoperative follow-up setting might be the various inflammatory changes that can develop locally after resection, such as in the mediastinum or at the surgical margin, since these changes often cause a high FDG uptake and result in false-positive findings. Inflammatory changes gradually disappear after resection, but Kanzaki et $\mathrm{al}^{47}$ reported that inflammatory changes were the main reason for falsepositive findings even when the PET/CT examinations were performed 6 months after resection. Choi et al ${ }^{13}$ also reported a false-positive rate of $13.4 \%$ for PET/CT in a postoperative follow-up setting.

Table I Follow-up surveillance guidelines recommended by medical societies

\begin{tabular}{|c|c|c|c|c|c|c|c|c|c|c|c|c|c|}
\hline & \multicolumn{13}{|c|}{ Time after resection (month) } \\
\hline & 6 & 9 & 12 & 15 & 18 & 21 & 24 & 30 & 36 & 42 & 48 & 54 & 60 \\
\hline \multicolumn{14}{|l|}{$\mathrm{NCCN}$} \\
\hline Physical examination & - & & $\bullet$ & & $\bullet$ & & $\bullet$ & & $\bullet$ & & $\bullet$ & & $\bullet$ \\
\hline (Enhanced) CT & $(\bullet)$ & & • & & $(\bullet)$ & & - & & • & & $\bullet$ & & • \\
\hline \multicolumn{14}{|l|}{$\mathrm{ACCP}$} \\
\hline Physical examination & • & & • & & $\bullet$ & & $\bullet$ & & $\bullet$ & & • & & • \\
\hline Radiograph or CT & $\bullet$ & & • & & $\bullet$ & & $\bullet$ & & $\bullet$ & & - & & $\bullet$ \\
\hline \multicolumn{14}{|l|}{ ESMO } \\
\hline Physical examination & - & & $\bullet$ & & $\bullet$ & & $\bullet$ & & $\bullet$ & & - & & $\bullet$ \\
\hline (Enhanced) CT & & & - & & & & $\bullet$ & & $\bullet$ & & - & & - \\
\hline \multicolumn{14}{|l|}{ ACR } \\
\hline Physical examination & $\bullet$ & $\bullet$ & - & - & $\bullet$ & $\bullet$ & $\bullet$ & $\bullet$ & $\bullet$ & $\bullet$ & $\bullet$ & $\bullet$ & $\bullet$ \\
\hline Chest radiograph & - & $\bullet$ & & • & - & - & & - & & • & & • & \\
\hline CT & & & - & & & & $\bullet$ & & $\bullet$ & & - & & - \\
\hline
\end{tabular}

Note: $(\cdot)$ indicates optional.

Abbreviations: NCCN, National Comprehensive Cancer Network; CT, computed tomography; ACCP, American College of Chest Physicians; ESMO, European Society for Medical Oncology; ACR, American College of Rheumatology. 


\section{Post radiotherapy}

The evaluation of local recurrence after radiotherapy is more complicated in patients than after resection, since the main tumor and/or lymph nodes are still present after radiation and are likely to be affected by inflammation and/or fibrosis. .8,49 $^{4}$ Several studies have used PET/CT as a follow-up modality after stereotactic radiotherapy and reported difficulty in diagnosing recurrences based on FDG values observed at a single time point. ${ }^{50-52}$ Mohammed et al ${ }^{53}$ conducted a systematic review and reported that recurrences should be suspected if sequential opacity enlargement and a standardized uptake value of $\geq 5$ were observed on repeated PET/ CT examinations.

\section{Postdefinitive chemoradiotherapy}

Several studies have evaluated the efficacy of PET/CT after definitive chemoradiotherapy, but the intent of these studies was to investigate the use of PET/CT as an indicator of tumor response to treatment or as a predictor of patient survival, rather than as a follow-up modality. ${ }^{54-56}$

\section{Distant metastasis}

The ability to detect distant metastasis in a follow-up setting is considered to be an advantage of PET/CT compared to the conventional follow-up modalities. However, it should be noted that although brain is the frequent site of metastasis, detection of brain metastasis with PET/CT has limitation, similar to its use in pretreatment staging.

Another advantage of PET/CT is its ability to detect asymptomatic second malignancies not only in the lung but also in other organs. Although PET/CT has some limitations as for health screening examinations, such as false positives and the difficulty to detect early cancer such as early gastric cancer or cervical cancer, PET/CT can screen almost the whole body noninvasively. The detection rate for a second malignancy using PET/CT in patients after resection has been reported to be $\sim 3 \%$ during the follow-up period. ${ }^{13,57,58}$

$\mathrm{PET} / \mathrm{CT}$ is equivalent or superior to conventional follow-up modalities for the detection of local recurrence and is superior for the detection of distant metastasis in a follow-up setting. Keidar et al ${ }^{59}$ prospectively evaluated the impact of PET/CT on the subsequent management in patients with suspected recurrent lung cancer. They reported that the PET/CT findings potentially modified the subsequent management (ie, eliminated the need for previously planned diagnostic procedures, resulted in the initiation of a previously unplanned treatment, or changed the previously planned therapeutic approach) in $29 \%$ of the patients. Similarly,

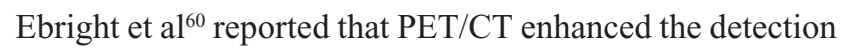
of local recurrence after stereotactic radiotherapy and might have influenced decisions regarding subsequent treatments performed for recurrence.

In contrast, Takenaka et a ${ }^{61}$ compared standard radiologic examinations (enhanced whole-body $\mathrm{CT}$ and bone scintigraphy) and PET/CT prospectively and reported that there was no difference between them in terms of sensitivity, specificity, and accuracy for the detection of recurrence. Choi et $\mathrm{al}^{13}$ also performed a cohort study of 358 patients in whom enhanced chest $\mathrm{CT}$ examinations were performed every 6 months and PET/CT was performed annually for 5 years after resection, and concluded that PET/CT seemed to be superior to chest $\mathrm{CT}$ but that PET/CT could fail to detect small or hypometabolic recurrences.

\section{Potential disadvantages or issues associated with the use of PET/CT in a follow-up surveillance setting Radiation exposure}

The radiation exposure from a single PET/CT examination is $\sim 11 \mathrm{mSV}$ (PET $=4 \mathrm{mSV}$ and $\mathrm{CT}=7 \mathrm{mSV}$ ). The exposure from a high-resolution CT examination is $\sim 7 \mathrm{mSV}$, while that of low-dose CT is $2 \mathrm{mSV}$ and that of chest radiography is $0.05 \mathrm{mSV}$. Thus, radiation exposure from PET/CT is higher than that from conventional modalities. ${ }^{13,62}$ Brenner and Hall ${ }^{63}$ have warned that radiation exposure caused by medical examinations is associated with the risk of cancer. Excess radiation exposure from follow-up examinations should therefore be taken into consideration, especially in patients who might not be in a cancer-burdened state and are expected to have long life spans after curative-intent treatment.

\section{Cost implications}

The medical cost of PET/CT is $\sim$ US $\$ 850$ (=100,000 Yen), while that of chest radiography is $\$ 20$, of plain chest CT is $\$ 150$, of enhanced brain MRI is $\$ 250$, and of bone scintigraphy is $\$ 400$ under the current medical environment in Japan. While the medical cost of PET/CT might vary among countries, it is usually much more expensive than other examinations. Choi et a ${ }^{13}$ evaluated the additional medical cost caused by false-positive findings from PET/CT examinations and reported that 33 out of 247 patients (13.4\%) had undergone unnecessary examinations including needle biopsy, MRI, and bronchoscopy because of false-positive findings from a PET/ CT examination. Thus, the issue of medical cost should also be taken into consideration when evaluating the efficacy of follow-up examinations using PET/CT. 


\section{Survival benefit}

Another critical issue that might need to be discussed is the survival benefit and/or improvement in the quality of life arising from a PET/CT examination. A number of studies have evaluated the accuracy of PET/CT for the detection of recurrence and have demonstrated the superiority of PET/CT over conventional modalities. ${ }^{13,47,57,58}$ None of these studies, however, evaluated the survival benefit and/or improvement in quality of life after follow-up with PET/CT, and the significance of PET/CT follow-up after curative-intent treatment remains unknown.

\section{Availability}

The last critical issue is the availability of PET/CT. This modality has spread widely throughout the world. As of 2015 , 1,570 and 466 PET/CT setups are active in US and Japan. ${ }^{64}$ However, not all patients can access PET/CT, since it is available only at select institutes, such as university hospitals and cancer centers. It is, therefore, difficult to recommend $\mathrm{PET} / \mathrm{CT}$ as a standard follow-up modality for use in general clinical practice.

\section{Summary of the applications of PET/CT in a follow-up surveillance setting}

1. PET/CT is considered to be superior to conventional modalities for the detection of asymptomatic recurrences, although false-positive results in local areas are often problematic.

2. PET/CT can modify the subsequent management that is performed in patients with suspected recurrences and might contribute to the appropriate selection of subsequent treatments.

3. Whether the use of PET/CT and the detection of asymptomatic recurrences in a follow-up setting improves the survival and/or quality of life of patients after curativeintent treatment has not yet been determined.

4. Both the radiation exposure and medical costs associated with PET/CT are higher than those of conventional follow-up modalities.

\section{Current status of PET/CT for follow-up surveillance}

According to the advantages described earlier, PET/CT could potentially become an alternative to conventional follow-up modalities after curative-intent treatment. However, several important issues remain to be solved, such as availability, the limitation of detection of brain metastasis, as well as unknown survival benefits and medical cost. In particular, performing repeated examinations without evidence of survival benefit in patients who might not have recurrence is questionable, taking its high medical cost into consideration. Considering these issues, it is premature to recommend PET/CT as a follow-up examination after curative-intent treatment in clinical practice at the moment.

\section{In the future}

1. Patient populations who are at high risk for recurrence and might receive a benefit from $\mathrm{PET} / \mathrm{CT}$ are to be identified.

2. The number of times to perform PET/CT, either once or twice, as well as their most efficient timing during the follow-up period is to be identified.

If these issues are solved, PET/CT will be accepted as one of the standard follow-up modalities after curative-intent treatment for lung cancer.

\section{Disclosure}

The authors report no conflicts of interest in this work.

\section{References}

1. Peuchot M, Libshitz HI. Pulmonary metastatic disease: radiologicsurgical correlation. Radiology. 1987;164(3):719-722.

2. Altorki N, Kent M, Pasmantier M. Detection of early-stage lung cancer: computed tomographic scan or chest radiograph? JThorac Cardiovasc Surg. 2001;121(6):1053-1057.

3. Zwirewich CV, Vedal S, Miller RR, Muller NL. Solitary pulmonary nodule: high-resolution $\mathrm{CT}$ and radiologic-pathologic correlation. Radiology. 1991;179(2):469-476.

4. Seemann MD, Staebler A, Beinert T, et al. Usefulness of morphological characteristics for the differentiation of benign from malignant solitary pulmonary lesions using HRCT. Eur Radiol. 1999;9(3):409-417.

5. Akeson P, Larsson EM, Kristoffersen DT, Jonsson E, Holtas S. Brain metastases - comparison of gadodiamide injection-enhanced MR imaging at standard and high dose, contrast-enhanced CT and noncontrast-enhanced MR imaging. Acta Radiol. 1995;36(3):300-306.

6. Vansteenkiste JF. Imaging in lung cancer: positron emission tomography scan. Eur Respir J Suppl. 2002;35:49s-60s.

7. Dupont P, Orban GA, Vogels R, et al. Different perceptual tasks performed with the same visual stimulus attribute activate different regions of the human brain: a positron emission tomography study. Proc Natl Acad Sci U S A. 1993;90(23):10927-10931.

8. Mortelmans L, Vanhaecke J, Lesaffre E, et al. Evaluation of the effect of thrombolytic treatment on infarct size and left ventricular function by enzymatic, scintigraphic, and angiographic methods. The European Cooperative Study Group for Recombinant Tissue Type Plasminogen Activator. Am Heart J. 1990;119(6):1231-1237.

9. Nolop KB, Rhodes CG, Brudin LH, et al. Glucose utilization in vivo by human pulmonary neoplasms. Cancer. 1987;60(11):2682-2689.

10. Nelson CA, Wang JQ, Leav I, Crane PD. The interaction among glucose transport, hexokinase, and glucose-6-phosphatase with respect to $3 \mathrm{H}-2$-deoxyglucose retention in murine tumor models. Nucl Med Biol. 1996;23(4):533-541.

11. Pauwels EK, McCready VR, Stoot JH, van Deurzen DF. The mechanism of accumulation of tumour-localising radiopharmaceuticals. Eur J Nucl Med. 1998;25(3):277-305. 
12. Wahl RL, Hutchins GD, Buchsbaum DJ, Liebert M, Grossman HB, Fisher S. 18F-2-deoxy-2-fluoro-D-glucose uptake into human tumor xenografts. Feasibility studies for cancer imaging with positronemission tomography. Cancer. 1991;67(6):1544-1550.

13. Choi SH, Kim YT, Kim SK, et al. Positron emission tomographycomputed tomography for postoperative surveillance in non-small cell lung cancer. Ann Thorac Surg. 2011;92(5):1826-1832; discussion1832.

14. Liao S, Penney BC, Wroblewski K, et al. Prognostic value of metabolic tumor burden on 18F-FDG PET in nonsurgical patients with non-small cell lung cancer. Eur J Nucl Med Mol Imaging. 2012;39(1):27-38.

15. Mac Manus MP, Hicks RJ, Matthews JP, et al. Positron emission tomography is superior to computed tomography scanning for response-assessment after radical radiotherapy or chemoradiotherapy in patients with non-small-cell lung cancer. J Clin Oncol. 2003;21(7): $1285-1292$.

16. Lee YJ, Cho A, Cho BC, et al. High tumor metabolic activity as measured by fluorodeoxyglucose positron emission tomography is associated with poor prognosis in limited and extensive stage small-cell lung cancer. Clin Cancer Res. 2009;15(7):2426-2432.

17. Cronin P, Dwamena BA, Kelly AM, Carlos RC. Solitary pulmonary nodules: meta-analytic comparison of cross-sectional imaging modalities for diagnosis of malignancy. Radiology. 2008;246(3):772-782.

18. Prauer HW, Weber WA, Romer W, Treumann T, Ziegler SI, Schwaiger M. Controlled prospective study of positron emission tomography using the glucose analogue [18f]fluorodeoxyglucose in the evaluation of pulmonary nodules. Br J Surg. 1998;85(11):1506-1511.

19. Lowe VJ, Duhaylongsod FG, Patz EF, et al. Pulmonary abnormalities and PET data analysis: a retrospective study. Radiology. 1997; 202(2):435-439

20. Kang F, Wang S, Tian F, et al. Comparing the diagnostic potential of 68Ga-Alfatide II and 18F-FDG in differentiating between non-small cell lung cancer (NSCLC) and tuberculosis patients. J Nucl Med. Epub 2015 Dec 30.

21. Rayamajhi S, Mittal B, Maturu V, et al. 18F-FDG and 18F-FLT PET/ CT imaging in the characterization of mediastinal lymph nodes. Ann Nucl Med. 2016;30(3):207-216.

22. Vansteenkiste JF, Stroobants SG. The role of positron emission tomography with $18 \mathrm{~F}$-fluoro-2-deoxy-D-glucose in respiratory oncology. Eur Respir J. 2001;17(4):802-820.

23. Fischer BM, Mortensen J, Hojgaard L. Positron emission tomography in the diagnosis and staging of lung cancer: a systematic, quantitative review. Lancet Oncol. 2001;2(11):659-666.

24. Bryant AS, Cerfolio RJ. The maximum standardized uptake values on integrated FDG-PET/CT is useful in differentiating benign from malignant pulmonary nodules. Ann Thorac Surg. 2006;82(3):1016-1020.

25. Wu HB, Wang L, Wang QS, et al. Adenocarcinoma with BAC features presented as the nonsolid nodule is prone to be false-negative on $18 \mathrm{~F}$ FDG PET/CT. Biomed Res Int. 2015;2015:243681.

26. Kim TJ, Park CM, Goo JM, Lee KW. Is there a role for FDG PET in the management of lung cancer manifesting predominantly as ground-glass opacity? AJR Am J Roentgenol. 2012;198(1):83-88.

27. Birim O, Kappetein AP, Stijnen T, Bogers AJ. Meta-analysis of positron emission tomographic and computed tomographic imaging in detecting mediastinal lymph node metastases in nonsmall cell lung cancer. Ann Thorac Surg. 2005;79(1):375-382.

28. van Tinteren H, Hoekstra OS, Smit EF, et al. Effectiveness of positron emission tomography in the preoperative assessment of patients with suspected non-small-cell lung cancer: the PLUS multicentre randomised trial. Lancet. 2002;359(9315):1388-1393.

29. Silvestri GA, Gould MK, Margolis ML, et al; American College of Chest Physicians. Noninvasive staging of non-small cell lung cancer: ACCP evidenced-based clinical practice guidelines (2nd edition). Chest. 2007;132(3 suppl):178S-201S.

30. Gould MK, Kuschner WG, Rydzak CE, et al. Test performance of positron emission tomography and computed tomography for mediastinal staging in patients with non-small-cell lung cancer: a meta-analysis. Ann Intern Med. 2003;139(11):879-892.
31. Bury T, Dowlati A, Paulus P, et al. Evaluation of the solitary pulmonary nodule by positron emission tomography imaging. Eur Respir $J$. 1996;9(3):410-414.

32. Pieterman RM, van Putten JW, Meuzelaar JJ, et al. Preoperative staging of non-small-cell lung cancer with positron-emission tomography. N Engl J Med. 2000;343(4):254-261.

33. Paul NS, Ley S, Metser U. Optimal imaging protocols for lung cancer staging: CT, PET, MR imaging, and the role of imaging. Radiol Clin North Am. 2012;50(5):935-949.

34. Palm I, Hellwig D, Leutz M, et al. Diagnostische Aussagekraft der Positronen-Emissions-Tomographie (PET) bei zerebralen Metastasen von Bronchialkarzinomen. [Brain metastases of lung cancer: diagnostic accuracy of positron emission tomography with fluorodeoxyglucose (FDG-PET)]. Med Klin (Munich). 1999;94(4):224-227. German.

35. Na II, Lee TH, Choe DH, et al. A diagnostic model to detect silent brain metastases in patients with non-small cell lung cancer. Eur J Cancer. 2008;44(16):2411-2417.

36. Chen W. Clinical applications of PET in brain tumors. J Nucl Med. 2007;48(9):1468-1481.

37. Schrevens L, Lorent N, Dooms C, Vansteenkiste J. The role of PET scan in diagnosis, staging, and management of non-small cell lung cancer. Oncologist. 2004;9(6):633-643.

38. Egermann U, Jaeggi K, Habicht JM, Perruchoud AP, Dalquen P, Soler M. Regular follow-up after curative resection of nonsmall cell lung cancer: a real benefit for patients? Eur Respir J. 2002;19(3): 464-468.

39. Virgo KS, Naunheim KS, McKirgan LW, Kissling ME, Lin JC, Johnson FE. Cost of patient follow-up after potentially curative lung cancer treatment. J Thorac Cardiovasc Surg. 1996;112(2): 356-363.

40. Walsh GL, O'Connor M, Willis KM, et al. Is follow-up of lung cancer patients after resection medically indicated and costeffective? Ann Thorac Surg. 1995;60(6):1563-1570; discussion $1570-1562$.

41. Chiu CH, Chern MS, Wu MH, et al. Usefulness of low-dose spiral $\mathrm{CT}$ of the chest in regular follow-up of postoperative non-small cell lung cancer patients: preliminary report. J Thorac Cardiovasc Surg. 2003;125(6):1300-1305.

42. Westeel V, Choma D, Clement F, et al. Relevance of an intensive postoperative follow-up after surgery for non-small cell lung cancer. Ann Thorac Surg. 2000;70(4):1185-1190.

43. Colt HG, Murgu SD, Korst RJ, Slatore CG, Unger M, Quadrelli S. Follow-up and surveillance of the patient with lung cancer after curativeintent therapy. Chest. 2013;143(5_suppl):e437S-e454S.

44. Vansteenkiste J, Crino L, Dooms C, et al. 2nd ESMO Consensus Conference on Lung Cancer: early-stage non-small-cell lung cancer consensus on diagnosis, treatment and follow-up. Ann Oncol. 2014; 25(8):1462-1474.

45. Sause WT, Byhardt RW, Curran WJ Jr, et al. Follow-up of non-small cell lung cancer. American College of Radiology. ACR Appropriateness Criteria. Radiology. 2000;215:1363-1372.

46. National Comprehensive Cancer Network [homepage on the Internet]. Clinical Practice Guidelines for Non-Small Cell Lung Cancer. Available from: www.nccn.org/patients. Accessed February 26, 2016.

47. Kanzaki R, Higashiyama M, Maeda J, et al. Clinical value of F18fluorodeoxyglucose positron emission tomography-computed tomography in patients with non-small cell lung cancer after potentially curative surgery: experience with 241 patients. Interact Cardiovasc Thorac Surg. 2010;10(6):1009-1014.

48. Dahele M, Palma D, Lagerwaard F, Slotman B, Senan S. Radiological changes after stereotactic radiotherapy for stage I lung cancer. JThorac Oncol. 2011;6(7):1221-1228.

49. Huang K, Dahele M, Senan S, et al. Radiographic changes after lung stereotactic ablative radiotherapy (SABR) - can we distinguish recurrence from fibrosis? A systematic review of the literature. Radiother Oncol. 2012;102(3):335-342. 
50. Henderson MA, Hoopes DJ, Fletcher JW, et al. A pilot trial of serial $18 \mathrm{~F}$-fluorodeoxyglucose positron emission tomography in patients with medically inoperable stage I non-small-cell lung cancer treated with hypofractionated stereotactic body radiotherapy. Int J Radiat Oncol Biol Phys. 2010;76(3):789-795.

51. Vahdat S, Oermann EK, Collins SP, et al. CyberKnife radiosurgery for inoperable stage IA non-small cell lung cancer: $18 \mathrm{~F}$-fluorodeoxyglucose positron emission tomography/computed tomography serial tumor response assessment. J Hematol Oncol. 2010;3:6.

52. Matsuo Y, Nakamoto Y, Nagata Y, et al. Characterization of FDGPET images after stereotactic body radiation therapy for lung cancer. Radiother Oncol. 2010;97(2):200-204.

53. Mohammed N, Grills IS, Wong CY, et al. Radiographic and metabolic response rates following image-guided stereotactic radiotherapy for lung tumors. Radiother Oncol. 2011;99(1):18-22.

54. Hicks RJ, Mac Manus MP, Matthews JP, et al. Early FDG-PET imaging after radical radiotherapy for non-small-cell lung cancer: inflammatory changes in normal tissues correlate with tumor response and do not confound therapeutic response evaluation. Int J Radiat Oncol Biol Phys. 2004;60(2):412-418.

55. Machtay M, Duan F, Siegel BA, et al. Prediction of survival by [18F] fluorodeoxyglucose positron emission tomography in patients with locally advanced non-small-cell lung cancer undergoing definitive chemoradiation therapy: results of the ACRIN 6668/RTOG 0235 trial. $J$ Clin Oncol. 2013;31(30):3823-3830.

56. van Loon J, Grutters J, Wanders R, et al. Follow-up with 18FDGPET-CT after radical radiotherapy with or without chemotherapy allows the detection of potentially curable progressive disease in nonsmall cell lung cancer patients: a prospective study. Eur J Cancer. 2009;45(4):588-595.
57. Cho S, Lee EB. A follow-up of integrated positron emission tomography/ computed tomography after curative resection of non-small-cell lung cancer in asymptomatic patients. J Thorac Cardiovasc Surg. 2010;139(6):1447-1451.

58. Toba H, Sakiyama S, Otsuka H, et al. 18F-fluorodeoxyglucose positron emission tomography/computed tomography is useful in postoperative follow-up of asymptomatic non-small-cell lung cancer patients. Interact Cardiovasc Thorac Surg. 2012;15(5):859-864.

59. Keidar Z, Haim N, Guralnik L, et al. PET/CT using 18F-FDG in suspected lung cancer recurrence: diagnostic value and impact on patient management. J Nucl Med. 2004;45(10):1640-1646.

60. Ebright MI, Russo GA, Gupta A, Subramaniam RM, Fernando HC, Kachnic LA. Positron emission tomography combined with diagnostic chest computed tomography enhances detection of regional recurrence after stereotactic body radiation therapy for early stage non-small cell lung cancer. J Thorac Cardiovasc Surg. 2013;145(3):709-715.

61. Takenaka D, Ohno Y, Koyama H, et al. Integrated FDG-PET/CT vs. standard radiological examinations: comparison of capability for assessment of postoperative recurrence in non-small cell lung cancer patients. Eur J Radiol. 2010;74(3):458-464.

62. Brix G, Lechel U, Glatting G, et al. Radiation exposure of patients undergoing whole-body dual-modality 18F-FDG PET/CT examinations. J Nucl Med. 2005;46(4):608-613.

63. Brenner DJ, Hall EJ. Computed tomography - an increasing source of radiation exposure. $N$ Engl J Med. 2007;357(22):2277-2284.

64. OECD. List of variable in OECD health statistics 2014, June 2014. Paris: OECD; 2014. Available from: http://www.oecd.org/els/health-systems/ List-of-variables-OECD-Health-Statistics-2014.pdf. Accessed April 1 , 2016.
Lung Cancer: Targets and Therapy

\section{Publish your work in this journal}

Lung Cancer: Targets and Therapy is an international, peer-reviewed, open access journal focusing on lung cancer research, identification of therapeutic targets and the optimal use of preventative and integrated treatment interventions to achieve improved outcomes, enhanced survival and quality of life for the cancer patient. Specific topics coveredin the journtinclude: Epidemiology, detection and Cellular research and biomarkers; Identification of biotargets and agents with nove

\section{Dovepress}

mechanisms of action; Optimal clinical use of existing anticancer agents, including combination therapies; Radiation and surgery; Palliative care; Patient adherence, quality of life, satisfaction; Health economic evaluations. The manuscript management system is completely online and includes a very quick and fair peer-review system. Visit http://www.dovepress.com/testimonials.php to read real quotes from published authors. 